INTUISI 12 (1) (2020)
INTUISI
$\begin{gathered}\text { InTHAL PSIKOLOGI ILMIAH } \\ \text { http://journal.unnes.ac.id/nju/index.php/INTUISI } \\ \text { Terindeks DOAJ: 2541-2965 }\end{gathered}$

\title{
FAKTOR EKSTERNAL DARI ORANGTUA ATAU FAKTOR INTERNAL DIRI SENDIRI YANG MEMPREDIKSI EMOSI MORAL REMAJA?
}

\author{
Margaretha Maria Shinta Pratiwi ${ }^{1 \bowtie}$, Subandi Subandi ${ }^{2}$, Maria Goretti Adiyanti ${ }^{2}$
}

${ }^{1}$ Fakultas Psikologi, Universitas Semarang, Indonesia

${ }^{2}$ Fakultas Psikologi, Universitas Gadjah Mada, Indonesia

\begin{tabular}{l} 
Info Artikel \\
\hline Sejarah Artikel: \\
Disubmit 17 April 2020 \\
Direvisi 19 April 2020 \\
Diterima 25 April 2020
\end{tabular}

Keywords:
Moral Emotion,
Perspective-Taking,
Parental Emotions
Socialization

\begin{abstract}
Abstrak
Emosi moral memegang peran penting yang berfungsi sebagai motif munculnya kecenderungan tindakan moral dan mengantisipasi pelanggaran moral remaja, dan mampu memikirkan kesejahteraan orang lain. Namun, belum ada penelitian yang mengkaji model yang memprediksi emosi moral remaja. Oleh karena itu, penelitian ini bertujuan: 1) Menguji model prediktif sosialisasi emosi orang tua yang dipersepsi oleh remaja dan perspective-taking terhadap emosi moral remaja; 2) Menguji peran perspective-taking mediator terhadap emosi moral remaja. Metode penelitian ini adalah metode kuantitatif. Pemilihan partisipan menggunakan teknik multistage sampling, partisipan berjumlah 936 remaja usia 12-18 tahun di Semarang yang diambil menggunakan Teknik analisis data menggunakan SEM PLS (Partial Least Square). Hasil penelitian ini menunjukkan: 1) Model prediktif sosialisasi emosi orang tua yang dipersepsi oleh remaja dan perspective-taking terhadap emosi moral remaja mampu membuktikan kesesuaian teoretis dan teruji berdasarkan data empiris. Berdasarkan pengujian model struktural, diperoleh data bahwa: a)Terdapat pengaruh signifikan sosialisasi emosi orangtua yang dipersepsi oleh remaja terhadap perspective-taking $(\gamma=0,353, \mathrm{~T}$-Stat $>1,96)$; b) Terdapat pengaruh signifikan perspective- taking terhadap emosi moral $(\beta=0,188, T$-Stat $>1,96)$; $)$ Terdapat pengaruh sosialisasi emosi orangtua yang dipersepsi oleh remaja emosi $\operatorname{moral}(\gamma=0,132$,T-Stat $>1,96)$; 2) Peran perspective-taking terbukti sebagai variabel mediator. Berdasarkan analisis data, maka dapat disimpulkan bahwa sosialisasi emosi orangtua yang dipersepsi oleh remaja dapat memengaruhi emosi moral secara langsung maupun secara tidak langsung melalui perspective-taking. Oleh karena itu, penelitian ini dapat memberikan manfaat bagi perkembangan teori terkait moral serta memberikan informasi pada masyarakat secara luas, remaja dan orangtua secara khusus berkaitan dengan faktor yang dapat memengaruhi perkembangan emosi moral dan fungsi dari emosi moral.

Abstract

Moral emotions hold an important role that functions as a motive for the emergence of moral acts and anticipates the moral violations of adolescents, and be able to think about the interests and welfare of other people. However, there has no studies that examine models that predict moral emotions in adolescents. Therefore, this study aims to: 1) Test the predictive model of parental emotions socialization perceived by adolescents and perspective-taking on adolescent moral emotions; 2) Test the role of perspective-taking as mediators, mediator between parental emotion socialization and adolescent moral emotion. The research method used is quantitative. Partisipant selection was conducted through multi-stage sampling, 936 teenagers aged 12-18 years in Semarang. The statistical data analysis used is SEM PLS (Partial Least Square): The research results indicate: 1) The predictive model of parental emotions socialization perceived by adolescents and perspective-taking on adolescent moral emotions can prove theoretical and tested suitability based on empirical data. Based on structural testing of the model, the data obtained that: a) There was a significant influence on parental socialization perceived by adolescents on perspective-taking $(\gamma=$ 0.353, T-Stat> 1.96); b) There was a significant influence of perspective-taking on moral emotions ( $\beta=$ $0.188, T$-Stat> 1.96); c) There was an influence of parental socialization of emotions perceived by adolescents moral emotions $(\gamma=0.132$, T-Stat $>1.96) s$; 2) The role of perspective-taking is proven as a mediator variable. Based on data analysis, it can be concluded that the parental emotions socialization perceived by adolescents can influence moral emotions directly or indirectly through perspective-taking. Therefore, this study can provide benefits for the development of moral theory, and provide information to the wider community, adolescents and parents specifically related to factors that can influence the development of moral emotions and the function of moral emotions.
\end{abstract}

(C) 2020 Universitas Negeri Semarang

\begin{tabular}{lr}
\hline Alamat korespondensi: & p-ISSN 2086-0803 \\
Fakultas Psikologi, Universitas Semarang, & e-ISSN 2541-2965 \\
Jl. Soekarno-Hatta, Semarang Indonesia & \\
shinta@usm.ac.id & \\
\hline
\end{tabular}




\section{PENDAHULUAN}

Secara umum moralitas dapat dikaitkan dengan nilai kemanusiaan dan berkaitan dengan perilaku yang bisa atau tidak bisa dilakukan. Salah satu domain yang penting adalah emosi moral yang berperan dalam mengantisipasi munculnya pelanggaran moral dan motif penting bagi kecenderungan tindakan moral (Malti, Keller, Gummerum, \& Buchmann, 2009; Spruit, Schalkwijk, Vugt, \& Stams, 2016). Memahami pengalaman moral bukan hanya mengetahui daftar aturan-aturan dan norma-norma yang ideal saja, tetapi juga kuatnya emosi yang dapat yang menjalankan regulasi moral dari evaluasi diri dan tindakantindakan (Sheikh \& Janoff-Bulman, 2010). Pendapat tersebut semakin diperkuat dengan beberapa temuan yang menjelaskan bahwa emosi moral lebih penting dalam perkembangan moral walaupun penalaran tetap memiliki peran (Greene \& Haidt, 2002; Johnston \& Krettenauer, 2011; Krettenauer \& Eichler, 2006; Malti \& Krettenauer, 2013; Tangney, Stuewig, \& Mashek, 2007).

Emosi moral merupakan pecahan dari emosi dasar yang memiliki keterkaitan dengan kepentingan atau kesejahteraan orang lain bukan diri sendiri sebagai agen (Haidt, 2003; Prinz, 2007). Emosi moral merupakan kondisi dimana individu bereaksi secara intuitif dan emosional terhadap munculnya pelanggaran norma yang dapat muncul saat individu melihat peristiwa yang menggerakkan diri untuk menolong orang lain maupun melihat orang lain melakukan perbuatan baik sehingga menginspirasi untuk berbuat baik pula. Oleh karena itu, emosi moral berbeda dengan emosi dasar atau emosi biasa atau emosi non-moral.

Dua kriteria yang dapat membedakan emosi moral dengan emosi non-moral adalah disinterested elicitor dan tendensi perilaku prososial (Haidt, 2003). Kriteria pertama menjelaskan bahwa emosi moral dapat dipicu ketika agen tidak memiliki kepentingan pribadi yang melekat pada peristiwa tertentu. Sebaliknya, emosi biasa atau emosi non- moral mencari kesenangan dan menghindari rasa sakit seperti kebahagiaan dan ketakutan yang ditimbulkan ketika peristiwa yang lebih disukai atau tidak menguntungkan terjadi pada agen (atau individu atau kelompok yang diidentifikasi oleh agen). Kriteria kedua mengacu pada jenis tindakan dimana emosi moral memengaruhi agen untuk terlibat. Sementara kecenderungan tindakan emosi biasa atau non-moral diarahkan untuk membawa keadaan yang menyenangkan bagi diri sendiri. Emosi moral menempatkan individu untuk memiliki motivasi yang meningkatkan kecenderungan untuk terlibat dalam tindakan pro-sosial yang diarahkan pada kepentingan orang lain.

Adapun beberapa bentuk emosi moral yaitu malu, rasa bersalah, bangga (Haidt, 2003; Stets \& Turner, 2006; Tangney \& Dearing, 2002; Tangney \& Tracy, 2011; Tangney et al., 2007; Wikström, 2015); rasa hina, marah, jijik, iba, syukur, elevasi (Haidt, 2002; Stets \& Turner,2006); takut \& cinta (Haidt, 2003). Menurut Weiner (2001) ada dua belas bentuk emosi moral: kekaguman, kemarahan, kecemburuan, iri hati, schadenfreude (merupakan perasaan senang atau puas karena melihat atau mendengar orang lain yang sedang mengalami kesulitan, kegagalan atau kehinaan), terima kasih, rasa bersalah, kemarahan terhadap ketidakadilan atau iritasi, penghinaan, penyesalan, terhina, simpati/ kasihan. Namun demikian, emosi yang dianggap dijadikan tolok ukur dalam menentukan perilaku dan moralitas adalah emosi malu, rasa bersalah, dan bangga (Sheikh \& Janoff-Bulman, 2010, Tangney \& Dearing, 2002; Tangney et al., 2007; Wikström, 2015). Remaja seharusnya memiliki emosi moral saat dihadapkan pada persoalan atau konflik moral agar dapat menentukan perilaku moral yang tepat. Namun kenyataannya, berdasarkan survei awal pada 1025 remaja di Semarang dengan menggunakan induksi dilema moral untuk mengetahui emosi moral yang muncul guna 
pengambilan keputusan moral, hasilnya menunjukkan bahwa hanya 136 remaja $(0,13$ persen dari 1025 remaja) yang mampu merasakan emosi moral. Hasil penelitian tersebut menunjukkan bahwa sebagian besar remaja kurang memiliki emosi moral sebagai dasar untuk pengambilan keputusan moral, padahal remaja diharapkan memiliki emosi moral.

Emosi moral dapat ditularkan dari satu individu kepada individu lainnya melalui proses sosialisasi. Sosialisasi dan perkembangan moralitas tidak terbatas pada masa kanak-kanak, tetapi terus terjadi pada masa remaja (Wikstrom 2015). Sosialisasi penting untuk menginternalisasikan norma-norma sosial, perkembangan pikiran, dan perkembangan emosi (Henslin, 2013; KlimesDougan \& Zeman, 2007). Remaja belajar tentang dunia emosional melalui berbagai interaksi dengan anggota keluarga, guru, dan teman-teman (Zeman, Cassano, \& Adrian, 2017). Proses transaksional ini dikenal sebagai sosialisasi emosi yang dimulai sejak awal kehidupan dan berlanjut sepanjang masa remaja. Remaja dapat belajar mengenali, memberi label, dan mengelola ekspresi emosi yang sesuai dengan norma sosial melalui proses sosialisasi emosi (Morris, Silk, Steinberg, Myers, \& Robinson, 2007; Eisenberg, Cumberland, \& Spinrad, 1998; Halberstadt, 1986; Shipman, Zeman, Nesin, \& Fitzgerald, 2003).

Sosialisasi emosi adalah proses yang sistematis dan berkesinambungan pada perkembangan sosio-emosional remaja (Klimes-Dougan \& Zeman 2007). Proses sosialisasi emosi dari orang tua dapat dilakukan melalui praktik pengasuhan yang berhubungan dengan emosi. Orangtua dapat membantu anak untuk belajar memahami, mengenal, dan menampilkan emosi yang tepat pada saat remaja menghadapi masalah atau dilema moral. Sosialisasi emosi orangtua merupakan praktik pengasuhan yang berhubungan dengan emosi anak, khususnya tentang bagaimana orangtua mensosialisasikan emosi moral yang dimiliki orangtua maupun yang diharapkan dimiliki oleh anak (Tangney $\&$ Dearing, 2002). Sosialisasi emosi orangtua mengacu pada bagaimana orangtua membantu anak untuk belajar, memahami, mengatur, mengatasi, mengekspresikan emosi, dan mendiskusikan emosi kepada anak (Eisenberg et.al.,1998; Halberstadt, 1986).

Emosi moral merupakan emosi yang kompleks secara kognitif dan memerlukan keterampilan dari aspek kognitif. Remaja memerlukan kemampuan mengambil berbagai pertimbangan yang bervariasi sesuai dengan situasi yang dihadapi (Krettenauer \& Eichler, 2006) dan mengkoordinasikan perspektif yang saling bertentangan antara dirinya dengan pandangan orang lain (Malti \& Ongley, 2015) Oleh karena itu, remaja diharapkan memiliki perspective-taking. Perspective-taking merupakan salah satu cara remaja untuk mengevaluasi isi yang disampaikan oleh agen sosialisasi agar terjadi proses internalisasi. Salah satu cara remaja mengevaluasi isi yang disampaikan oleh agen sosialisasi adalah mampu mengerti apa yang dipikirkan atau yang dikehendaki agen sosialisasi ataupun mampu mendudukkan diri sendiri pada posisi agen atau orang lain. Apabila individu tidak mampu membuat penilaian tentang suatu peristiwa atau masalah atau dilema moral, maka akan mengalami kesulitan dalam memunculkan emosi moral.

Selama beberapa dekade, penelitian psikologi moral masih berfokus pada penalaran moral dan secara khusus pada masalah hak, keadilan, dan kejujuran (Krebs, 2008). Sebagian besar penelitian mengacu pada teori perkembangan moral dari Piaget dan Kohlberg yang lebih fokus pada peran kognisi dalam perkembangan dan terjadinya kematangan moral. Berbagai hasil penelitian menjelaskan bahwa penalaran moral atau penilaian moral berhubungan dengan pelanggaran moral (Piaget, 1965; Stams et al., 2006). Namun studi lain justru 
menunjukkan bahwa penalaran moral bukan merupakan domain yang memengaruhi perilaku pelanggaran moral (Hawley, 2003; Leenders \& Brugman, 2005). Hal tersebut menunjukkan bahwa kelemahan dari teori Piaget dan Kohlbeg adalah kurang mementingkan aspek fungsi moral dan emosi moral, serta mengabaikan studi sistematis emosi dan perannya dalam moralitas anak dan remaja (Haidt, 2003; Santrock, 2016) padahal emosi moral dianggap sebagai domain perkembangan moral yang penting. Penelitian yang fokus pada emosi moral pun sering diabaikan (Santrock, 2007; Tangney, Stuewig, \& Mashek, 2007).

Pentingnya emosi moral kurang diimbangi dengan penelitian yang memposisikan emosi moral sebagai variabel endogen baik di luar Indonesia maupun di Indonesia. Beberapa penelitian emosi moral yang dilakukan di Indonesia adalah penelitian dari Ramdhani (2016) yang meneliti tentang pengaruh emosi moral dengan perundungansiber. Penelitian Septiana (2018) menunjukkan bahwa emosi moral rasa bersalah memiliki pengaruh terhadap kecurangan akademik. Penelitian lain yang dilakukan oleh Widyarini (2016) menunjukkan bahwa emosi moral positif yang diinduksi (elevasi, kekaguman, dan kebahagiaan) tidak memiliki efek yang berbeda pada pengambilan keputusan etis. Namun, tanggapan emosional yang terdiri dari inspired, touched, dan affected memiliki perbedaan rata-rata yang signifikan dalam pengambilan keputusan etis. Penelitian Widyarini (2017) menunjukkan bahwa emosi moral yang berbeda memiliki efek yang berbeda pada pengambilan keputusan etis. Jijik sebagai emosi moral memengaruhi pengambilan keputusan etis secara signifikan lebih besar daripada rasa marah. Beberapa contoh penelitian tersebut menjelaskan bahwa variabel emosi moral diteliti sebagai variabel eksogen bukan variabel endogen. Emosi moral memengaruhi variabel lain seperti perundungan-siber, kecurangan akademik, dan pengambilan keputusan etis. Penetian-penelitian tersebut membuktikan bahwa belum ada penelitian di Indonesia yang meneliti emosi moral sebagai variabel endogen. Oleh karena itu, emosi moral masih perlu diteliti lebih lanjut sebagai variabel endogen dan mengetahui variabel eksogen apa yang dapat memengaruhi emosi moral.

Tujuan penelitian ini adalah:1) menguji model prediktif sosialisasi emosi orangtua yang dipersepsi oleh remaja dan perspective-taking terhadap emosi moral remaja; 2) menguji peran perspective-taking sebagai variabel meditor. Oleh karena itu, hipotesis penelitian yang diajukan adalah sosiliasasi emosi orangtua yang dipersepsi oleh remaja memengaruhi emosi moral secara langsung maupun secara tidak langsung melalui perspective-taking. Diharapkan penelitian ini dapat memberikan manfaat bagi perkembangan teori terkait moral serta memberikan informasi pada masyarakat secara luas, remaja dan orangtua secara khusus berkaitan dengan faktor yang dapat memengaruhi perkembangan emosi moral dan fungsi dari emosi moral.

\section{METODE}

Penelitian ini menggunakan metode kuantitatif dengan desain penelitian korelasional. Variabel penelitian terdiri dari variabel indogen (Y) adalah emosi moral, variabel eksogen $(\mathrm{X})$ adalah sosialisasi emosi orangtua, dan variabel moderator (M) adalah perspective-taking. Emosi moral merupakan pecahan dari emosi dasar yang muncul karena adanya disinterested elicitor dan adanya tendensi perilaku prososial yang berfungsi untuk memotivasi seseorang berperilaku moral atau mengantisipasi munculnya pelanggaran moral yang berkaitan dengan kepentingan atau kesejahteraan orang lain. Emosi moral pada remaja akan diukur menggunakan skala emosi moral yang disusun sendiri oleh peneliti dengan memberikan 
induksi berupa 18 cerita yang mengandung dilemma moral hipotetis dengan tema-tema moral dan tendensi prilaku prososial. Pada masing-masing cerita akan disajikan respon emosi yang sesuai. Adapun bentuk-bentuk respon emosi moral yaitu marah, malu, jijik, rasa bersalah, bangga, rasa syukur, elevasi, dan compassion. Pilihan jawabannya adalah Sama sekali tidak merasakan sampai sangat kuat emosi yang dirasakan dengan rentang skor $1-5$. Contoh salah satu cerita yang berisi dilema moral bertema tendensi perilaku prososial:

Bayangkan, bila saat ini adalah waktu akhir semester di sekolah dan kamu sedang menjalani ujian akhir. Suatu pagi, dalam perjalanan ke sekolah, kamu melihat seorang ibu yang terjatuh. Kamu tidak mengenal wanita tua tersebut secara pribadi. Secara kebetulan, kamulah yang dekat dengan ibu tersebut. Apabila membantu wanita tersebut, maka akan membuatmu terlambat untuk ujian hari ini. Jadi kamu pergi begitu saja tanpa membantu walaupun banyak orang yang melihatmu. Bagaimana perasaanmu sendiri setelah kamu membayangkan kejadian di atas?

Partisipan diminta memilih satu dari lima alternatif jawaban yaitu Sama sekali tidak merasakan, emosi yang dirasakan lemah, Cukup kuat emosi yang dirasakan, Emosi yang dirasakan kuat, atau Sangat kuat emosi yang dirasakan pada masing-masing respon emosi, misal: a) Saya merasa bersalah karena tidak membantu wanita tersebut, b) Saya merasa malu karena sebagian orang-orang melihat saya yang pergi saja meninggalkan ibu tersebut, c) Saya merasa menyesal karena pergi saja tidak membantu ibu tersebut.

Sosialisasi emosi orangtua adalah proses mensosialisasikan emosi yang dilakukan orangtua kepada anak melalui praktik-praktik pengasuhan. Sosialisasi emosi orang tua diukur menggunakan skala sosialisasi emosi yang disusun sendiri oleh peneliti, terdiri dari 26 aitem dengan cara-cara pengasuhan sebagai berikut reaksi orangtua terhadap emosi anak-anak, diskusi, dan menunjukkan ekspresi emosi orangtua terhadap emosi remaja. Pilihan jawabannya adalah Sangat tidak sesuai sampai Sangat sesuai dengan rentang skor $1-5$. Contoh aitem: orang tua saya mengajarkan saya untuk bersyukur karena saya dapat menolong orang lain.

Perspective-taking pada remaja adalah kemampuan kognitif yang dimiliki remaja dalam mempertimbangkan persepsi orang lain dengan memperhatikan lingkungan sosial untuk memahami pikiran dan perasaan orang lain melalui sudut pandang orang lain. Perspective-taking diukur menggunakan skala perspective-taking yang disusun sendiri oleh peneliti, terdiri dari 24 aitem dengan dimensi perspective taking kognitif, prespective taking afektif, dan perspective-taking yang terkait dengan penilaian. Contoh item: Pemikiran orang lain belum tentu sama dengan pemikiran saya, sehingga saya berusaha memahami cara berpikirnya. Pilihan jawabannya adalah Sangat tidak sesuai sampai Sangat sesuai dengan rentang skor $1-5$.

Partisipan penelitian adalah remaja usia 12-18 tahun, laki-laki dan perempuan, warga negara Indonesia, bersekolah di SMP dan SMA di Semarang. Pengambilan data dilakukan di Semarang yang terbagi menjadi enam belas kecamatan yang terdiri dari 132.127 remaja berusia $12-18$ tahun $(64.448$ siswa usia 12-14 tahun yang bersekolah di jenjang SMP dan 67.679 siswa usia 15-18 tahun yang bersekolah di jenjang SMA). Berdasarkan data tersebut, peneliti menentukan jumlah minimal partisipan yang harus digunakan dalam penelitian. Penentuan jumlah sampel dilakukan menggunakan perhitungan dengan rumus sampling survey secara online melalui alamat https://www.surveysystem.com/sscalc.htm.

Berdasarkan rumus tersebut, maka minimal jumlah sampel adalah 400 remaja. Peneliti memutuskan untuk mengambil jumlah sampel 
kurang lebih mengalikan dua dari jumlah 400 agar jumlah data lebih representatif dan mewakili populasi.

Teknik pengambilan sampel adalah multistage sampling secara cross sectional. Tahap pertama yang dilakukan peneliti adalah melakukan random untuk memilih enam kecamatan dari enam belas kecamatan yang akan dijadikan lokasi penelitian. Tahap kedua adalah melakukan random untuk menentukan sekolah pada masing-masing kecamatan. Tahap ketiga adalah melakukan random untuk menentukan kelas pada masing-masing sekolah. Oleh karena pengambilan data dilakukan secara cross sectional, maka peneliti melakukan random kelas untuk masing-masing tingkatan agar memeroleh

\section{HASIL DAN PEMBAHASAN}

Berikut adalah data demografis yang diperoleh:

Tabel 1

Deskripsi partisipan penelitian ( $\mathrm{N}=936)$

\begin{tabular}{clcc}
\hline Variabel & \multicolumn{1}{c}{ Klasifikasi } & Frekuensi & Prosentase (Dalam \%) \\
\hline \multirow{2}{*}{ Jenis kelamin } & Laki-laki & 477 & 50,96 \\
\multirow{2}{*}{ Usia } & Perempuan & 459 & 49,04 \\
& 12 tahun & 119 & 12,71 \\
& 13 tahun & 162 & 17,31 \\
& 14 tahun & 173 & 18,48 \\
& 15 tahun & 151 & 16,13 \\
& 16 tahun & 159 & 16,99 \\
Pendidikan & 17 tahun & 134 & 14,32 \\
& 18 tahun & 38 & 4,06 \\
& SMP & 485 & 51,82 \\
& SMA & 451 & 48,18 \\
\hline
\end{tabular}

variasi usia 12 -18 tahun. Berdasarkan proses tersebut terpilih 936 partisipan usia 12-18 tahun yang dijadikan partisipan penelitian.

Teknik analisis dalam penelitian ini adalah SEM menggunakan program analisis statistik Partial Least Square (PLS) untuk mengevaluasi model prediktif. Evaluasi model terdiri dari dua bagian, yaitu evaluasi model pengukuran dan evaluasi model struktural (Ghozali \& Fuad, 2014). Teknik analisis dengan program PLS dipilih karena tujuan penelitian adalah memprediksi bukan untuk menguji model teoritik tetapi dapat juga untuk menjelaskan ada atau tidak adanya hubungan antar variabel laten, dan data tidak harus berdistribusi normal.
Berdasarkan deskripsi partisipan penelitian, diketahui bahwa jumlah antara partisipan laki-laki dan perempuan relatif sama, yaitu jumlah partisipan laki-laki adalah 477 (50,96 persen dari 936 remaja) dan jumlah partisipan perempuan adalah 459 (49,04 persen dari 936 remaja). Berdasarkan usia partisipan, diketahui bahwa jumlahnya relatif sama antara partisipan berusia 13-17 tahun yaitu berjumlah 151 sampai 173 partisipan (16,13 persen sampai 18,48 persen dari 936 remaja). Sedangkan partispan berusia 12 tahun berjumlah 119 (12,71 persen dari 936 remaja) dan yang paling sedikit adalah partisipan berusia 18 tahun $(4,06$ persen dari 936 remaja).

Tabel 2 menjelaskan tentang gambaran umum kategori emosi moral, perspective-taking, dan sosialisasi emosi orangtua pada remaja di Semarang. 
Tabel 2

Deskriptif kategori $(\mathrm{N}=936)$

\begin{tabular}{lccc}
\hline & \multicolumn{3}{c}{ Kategori (Dalam Persen) } \\
\cline { 2 - 4 } \multicolumn{1}{c}{ Variabel } & Tinggi & Sedang & Rendah \\
\hline Emosi Moral & 65,2 & 30,2 & 4,6 \\
Perspective-taking & 56 & 37,9 & 6,1 \\
Sosialisasi Emosi Orangtua & 74,4 & 24,1 & 1,5 \\
\hline
\end{tabular}

Berdasarkan tabel 2, emosi moral dengan kategori rendah sebesar 6,1 persen. pada remaja 65,2 persen pada kategori tinggi atau kuat, dengan kategori sedang 30,2 persen, dan pada kategori rendah 4,6 persen. Perspective-taking 56 persen dengan kategori Sosialisasi emosi orangtua yang dipersepsi oleh remaja 74,4 persen dalam kategori tinggi, pada kategori sedang 24,1 persen, dan pada kategori rendah 1,5 persen.

tinggi dengan kategori sedang 37,9 persen

Tabel 3

Deskripsi statistik data penelitian berdasarkan variabel penelitian ( $\mathrm{N}=936)$

\begin{tabular}{lcccc}
\multicolumn{1}{c}{ Variabel } & Rerata & Rerata & & \\
& Empirik & Hipotetik & SD Hipotetik & Kategori \\
\hline Emosi moral & 48,03 & 34 & 11 & Tinggi \\
Perspective-taking & 17,76 & 15 & 3 & Sedang \\
Sosialisasi emosi orangtua & 35,98 & 27 & 6 & Tinggi \\
\hline
\end{tabular}

Tabel 3 menjelaskan tentang deskripsi statistik data penelitian yang dihitung dengan membandingkan antara rerata empirik dengan rerata hipotetik untuk melihat kategori secara umum pada masing-masing variabel. Hasilnya menunjukkan bahwa emosi moral pada remaja termasuk dalam kategori tinggi, perspectivetaking termasuk dalam kategori sedang, dan sosialisasi emosi orangtua yang dipersepsi oleh remaja dalam kategori tinggi.

a. Evaluasi model pengukuran

Evaluasi model pengukuran dilakukan untuk menguji validitas konstruk dan reliabilitas alat ukur. Uji validitas dilakukan untuk mengetahui kemampuan alat ukur penelitian mengukur apa yang seharusnya diukur. Sedangkan uji reliabilitas digunakan untuk mengukur konsistensi responden dalam menjawab item pertanyaan dalam alat ukur penelitian. Pada penelitian ini model pengukuran yang akan dievaluasi terdiri dari konstruk reflektif. Evaluasi kualitas alat ukur dilakukan dengan uji validitas konstruk konvergen dan diskriminan. Validitas konvergen diperoleh dengan menghitung factor loading, AVE, dan composite reliability (CR), sedangkan validitas diskriminan dengan menghitung akar AVE dibandingkan korelasi antar variabel. Validitas konvergen pada indikator reflektif dianggap baik apabila memiliki nilai factor loading $>0,7$, dan Average Variance Extracted (AVE) $>0.5$. Namun demikian skor loading antara 0,4-0,7 dapat digunakan sepanjang skor AVE dan communality pada konstruk tersebut > 0,5 (Hair, Hult, Ringle, \& Sarstedt, 2017). Validitas diskriminan berhubungan dengan prinsip bahwa pengukuran-pengukuran konstruk yang berbeda seharusnya tidak berkorelasi tinggi. Validitas diskriminan dinilai berdasarkan cross loading pengukuran dengan konstruknya atau dengan membandingkan akar AVE untuk setiap konstruk dengan korelasi antara konstruk dengan konstruk lainnya dalam model (Fornell-Larcker method). Nilai akar AVE suatu konstruk harus lebih tinggi dari nilai korelasi tertinggi konstruk tersebut dengan konstruk lainnya. Uji reliabilitas dapat dilihat dari nilai composite reliability (CR). Suatu 
konstruk dianggap reliabel apabila nilai composite reliability >0.7 (Hair et al., 2017).

Tabel 4

Evaluasi model pengukuran

\begin{tabular}{lcccccc}
\hline \multicolumn{1}{c}{ Variabel } & $\begin{array}{c}\text { Jumlah } \\
\text { Item yang } \\
\text { Diuji }\end{array}$ & $\begin{array}{c}\text { Jumlah } \\
\text { Item } \\
\text { Valid }\end{array}$ & $\begin{array}{c}\text { Factor } \\
\text { Loading }\end{array}$ & AVE & $\begin{array}{c}\text { Composite } \\
\text { Reliability }\end{array}$ & Akar AVE \\
\hline Emosi Moral & 51 & 17 & $0,426-0,792$ & 0,500 & 0,943 & 0,707 \\
$\begin{array}{l}\text { Perspective-taking } \\
\text { Sosialisasi Emosi }\end{array}$ & 24 & 5 & $0,671-0,734$ & 0,504 & 0,835 & 0,710 \\
Orangtua & 26 & 9 & $0,634-0,776$ & 0,502 & 0,900 & 0,708 \\
\hline
\end{tabular}

Berdasarkan Tabel 4 maka skala emosi moral, skala perspective-taking, dan skala sosialisasi emosi orangtua telah memenuhi syarat validitas konvergen, validitas diskriminan, dan reliabilitas sehingga evaluasi model stuktural dapat dilakukan untuk menguji hipotesis penelitian.

Berdasarkan parameter uji validitas di atas, dapat disimpulkan bahwa alat ukur memenuhi kriteria validitas dan reliabilitas yang baik. Oleh karena itu evaluasi model dapat dilakukan. Structural atau Inner model dapat diukur dengan melihat nilai R-Square $\left(\mathrm{R}^{2}\right)$ untuk mengukur tingkat variasi perubahan variabel independen terhadap variabel dependen. Semakin tinggi nilai $\mathrm{R}^{2}$ berarti semakin baik model prediksi dari model Tabel 5

Nilai Koefisien Jalur Antar Variabel Penelitian penelitian yang diajukan. Kemudian langkah selanjutnya adalah estimasi koefisien jalur yang merupakan nilai estimasi untuk hubungan jalur dalam model struktural yang diperoleh dengan prosedur brootstrapping dengan nilai yang dianggap signifikan jika nilai $\mathrm{t}$ statistik lebih besar dari 1,96 (significance level 5\%) atau lebih besar dari 1,65 (significance level 10\%) untuk masingmasing hubungan jalurnya. Nilai path atau inner model menunjukkan tingkat signifikansi dalam pengujian hipotesis.

Nilai koefisien jalur (path coefficient) antar variabel yang ditunjukkan pada model struktural, menggambarkan kekuatan hubungan antar variabel.

\begin{tabular}{lcccc}
\hline \multicolumn{1}{c}{ Hubungan Variabel } & $\begin{array}{c}\text { Efek } \\
\text { Langsung }\end{array}$ & $\begin{array}{c}\text { Standart } \\
\text { Deviasi } \\
\text { (STDEV) }\end{array}$ & $\begin{array}{c}\text { T - } \\
\text { Statistik }\end{array}$ & Hasil \\
\hline Sosialisasi Emosi Orangtua $\rightarrow$ Emosi Moral & 0,132 & 0,045 & 2,947 & Signifikan \\
Sosialisasi Emosi Orangtua $\rightarrow$ Perspective-taking & 0,353 & 0,035 & 10,046 & Signifikan \\
Perspective-taking $\rightarrow$ Emosi Moral & 0,188 & 0,039 & 4,792 & Signifikan \\
\hline
\end{tabular}

Nilai $\mathrm{R}^{2}$ dapat digunakan untuk mengukur tingkat variasi perubahan (variabilitas) pada variabel endogen yang mampu dijelaskan oleh variabel eksogen, dimaknai dalam persentase.

Tabel 6

Nilai $R^{2}$ variabel endogen

\begin{tabular}{lcc}
\hline \multicolumn{1}{c}{ Variabel } & Nilai $\mathrm{R}^{2}$ & Kategori \\
\hline Emosi moral & 0,346 & Sedang \\
Perspective-taking & 0,231 & Lemah \\
\hline
\end{tabular}

Hasil pada Tabel 5 memberi arti bahwa emosi moral mampu dijelaskan oleh variabel eksogen (sosialisasi emosi orangtua) dan variabel mediator (perspective-taking) sebesar 34,6 persen. Variabel perspectivetaking dapat dijelaskan oleh variabel sosialisasi emosi moral dan kualitas pertemanan sebesar 23,1 persen. 
Nilai $f^{2}$ digunakan untuk melihat variabel laten eksogen terhadap laten seberapa substantif besarnya pengaruh endogen.

Tabel 7

Nilai $\mathrm{f}^{2}$

\begin{tabular}{lcc}
\hline \multicolumn{1}{c}{ Variabel } & Nilai f & Kategori \\
\hline Sosialisasi Emosi Orangtua $\rightarrow$ Emosi moral & 0,015 & Kecil \\
Sosialisasi Emosi Orangtua $\rightarrow$ Perspective-taking & 0,130 & Kecil \\
Perspective-taking $\rightarrow$ Emosi moral & 0,036 & Kecil \\
\hline
\end{tabular}

Tabel 7 memberi arti bahwa variabel sosialisasi emosi orangtua memiliki substantif pengaruh yang kecil untuk variabel perspective-taking; variabel sosialisasi emosi orangtua memiliki substantif pengaruh yang

Tabel 8

Nilai $Q^{2}$

\begin{tabular}{lcc}
\hline \multicolumn{1}{c}{ Variabel } & Nilai $^{2}$ & Kategori \\
\hline Emosi moral & 0,170 & Memiliki predictive relevance \\
Perspective-taking & 0,115 & Memiliki predictive relevance \\
\hline
\end{tabular}

Berdasarkan tabel 5 sampai 8 disimpulkan bahwa model emosi moral yang telah diuji terbukti sebagai model prediktif untuk menjelaskan faktor sosilisasi emosi orangtua yang dipersepsi oleh remaja

Tabel 9

Koefisien Regresi Efek Langsung, Efek Tidak Langsung dan Efek Total

\begin{tabular}{lccc}
\hline \multicolumn{1}{c}{ Pengaruh } & Efek Langsung & Efek Tidak Langsung & Efek Total \\
\hline Sosialisasi Emosi Orangtua $\rightarrow$ Emosi Moral & $0,132^{*}$ & 0,210 & 0,342 \\
Sosialisasi Emosi Orangtua $\rightarrow$ Perspective-taking & $0,353^{*}$ & & 0,353 \\
Perspective-taking $\rightarrow$ Emosi Moral & $0,188^{*}$ & & 0,188 \\
\hline Kererangan
\end{tabular}

Keterangan $(*=$ signifikan pada T-Statistics $>1,96)$

Hasil analisis pada tabel 9 menunjukkan pengaruh antar variabel baik secara langsung, tidak langsung dan pengaruh total.

Tabel 10

Hasil Uji Efek Mediasi Secara Khusus

\begin{tabular}{llccccc} 
& Pengaruh & & $\begin{array}{c}\text { Efek Tidak } \\
\text { Langsung }\end{array}$ & Efek Total & VAF & $\begin{array}{c}\text { Jenis } \\
\text { Mediasi }\end{array}$ \\
\hline $\begin{array}{l}\text { Sosialisasi } \\
\text { taking } \rightarrow \text { Emosi Orangtua }\end{array}$ & $\rightarrow$ & Perspective- & 0,066 & 0,198 & $33,5 \%$ & Parsial \\
\hline
\end{tabular}

Berdasar Tabel 10 menunjukkan bahwa variabel perspective-taking memiliki peran sebagai mediator secara parsial dalam menjelaskan pengaruh antara sosialisasi emosi orangtua terhadap emosi moral. kecil pada emosi moral secara langsung. Variabel perspective-taking memiliki substantif pengaruh yang kecil pada emosi moral. (variabel eksogen), dan perspective-taking (variabel mediator) yang dapat memengaruhi emosi moral. Oleh karena itu hipotesis penelitian dapat diterima. taking $\rightarrow$ Emosi Moral

Setelah melakukan evaluasi model struktural, maka dapat disimpulkan bahwa tujuan penelitian dapat terjawab yaitu: 1) Terbukti ada kesesuaian model prediktif sosialisasi emosi orangtua yang dipersepsi 
oleh remaja dan perspective-taking terhadap emosi moral remaja dengan data empiris; 2) Perspective-taking memiliki peran sebagai variabel meditor. Hipotesis penelitian ini terbukti yaitu ada pengaruh sosialisasi emosi orangtua yang dipersepsi oleh remaja secara langsung maupun secara tidak langsung melalui perspective-taking.

Penelitian ini membuktikan model prediktif yang diusulkan oleh peneliti dapat diterima. Peneliti dapat menemukan faktor eksternal dari orangtua yaitu melalui proses sosialisasi emosi orangtua dapat memengaruhi emosi moral secara langsung maupun tidak langsung melalui faktor internal remaja yaitu perspective-taking. Selama ini baru ada satu model emosi moral yang diformulasikan oleh Tracy dan Robins (2007). Hanya saja model yang dibangun bukan menjelaskan faktor eksternal apa saja yang dapat memengaruhi emosi moral, tetapi hanya menjelaskan dinamika faktor-faktor internal dalam diri individu. Model tersebut disebut sebagai model proses yang dibangun berdasarkan teori dan penelitian sebelumnya tentang atribusi kausal dan emosi, penilaian kognitif dan emosi (Lazarus, 1991; Smith \& Ellsworth, 1985); anteseden kognitif dari rasa malu, rasa bersalah, dan bangga (Lewis, 2008; Tangney, 1991); dan proses evaluasi diri (Higgins, 1987). Model tersebut lebih menjelaskan proses terbentuknya rasa malu, rasa bersalah, dan bangga.

Hasil penelitian ini dapat menjelaskan bahwa orangtua memiliki pengaruh bagi perkembangan remaja. Orangtua melalui cara pengasuhan yang tepat dapat mensosialisasikan emosi moral kepada remaja baik secara langsung maupun tidak langsung. Remaja dapat menginternalisasikan nilai-nilai moral maupun hal-hal yang berkaitan dengan moral atas bantuan orangtua melalui pengasuhan (Karmakar, 2015). Remaja membutuhkan masukan dari orangtua bukan pendiktean dari orangtua (Santrock, 2007). Orangtua dapat menjelaskan sesuatu kepada remaja dengan penjelasan dan alasan yang detail. Meningkatnya kemampuan kognitif pada remaja, membuat remaja ingin tahu apa yang disampaikan orangtua, tetapi secara detail dengan pemberian penjelasan dari orangtua.

Salah satu teori tentang sosialisasi emosi moral menjelaskan bahwa orang tua dapat mensosialisasikan gaya emosi yang dimiliki kepada remaja melalui keyakinan pengasuhan dan praktik pengasuhan (Bennett, Sullivan, \& Lewis, 2010; Eisenberg et al., 1998; Meesters, Muris, Dibbets, Cima, \& Lemmens, 2017; Parisette-Sparks, Bufferd, \& Klein, 2015; PuiKi, 2001; Tangney \& Dearing, 2002; Tangney et al., 2007). Sosialisasi dapat dilakukan secara langsung oleh orangtua melalui pembelajaran, pengkondisian, dan pengajaran didaktik; maupun secara tidak langsung melalui identifikasi, imitasi, dan pembelajaran sosial yang dapat diperoleh melalui pemahaman anak tentang pengalaman dan ekspresi emosi orang tua (Hastings, 2018). Praktik pengasuhan orangtua memainkan peran penting dalam menjelaskan hubungan antara gaya emosi yang dimiliki orangtua dengan yang dimiliki oleh anak. Orangtua merupakan agen sosialisasi primer bagi perkembangan nilai dan perilaku anak. Orangtua dapat mendukung anak dalam mengambil peran dan memahami kebutuhan emosinya. Remaja dapat belajar tentang standar, norma, dan harapan yang akan bermanfaat bagi pengalaman anak tentang rasa bangga, senang, rasa syukur, marah, rasa malu, dan rasa bersalah melalui orang tua. Artinya, dalam memahami standar perilaku, anak akan dibantu oleh orang dewasa yang menyampaikan harapan perilaku dalam pengalaman sehari-hari (Lagattuta \& Thompson, 2007).

Orangtua memiliki pengaruh besar dalam memunculkan emosi moral anak dengan memberikan dukungan emosional (Malti, Eisenberg, Kim, \& Buchmann, 2013). Orangtua yang mampu mempraktikkan cara 
pengasuhan yang tepat seperti bereaksi dengan tepat, merespon suatu peristiwa emosi dengan cara yang tidak menakutkan, melatih anak, berdiskusi tentang emosi yang tepat dalam merespon permasalahan moral, dan memberikan dukungan dapat membantu menumbuhkan emosi moral kepada anak (Dunn, 2006; Eisenberg, Cumberland, \& Spinrad, 1998; Grusec, 2006; Hoffman, 2000; Konchanska, Koenig, Barry, Kim, \& Yoon, 2010). Penelitian lain menunjukkan bahwa kedekatan orangtua dengan anak dan monitoring orang tua kepada anak dapat memberikan pengaruh yang signifikan terhadap perubahan individu dalam nilai-nilai moral dan emosi moral (Pauwels \& Svensson, 2015; Svensson, Pauwels, Weerman, \& Bruinsma, 2017).

Teori sosial kognitif dapat digunakan untuk menerangkan proses sosialisasi emosi moral (Tangney \& Dearing, 2002). Teori ini menjelaskan bahwa proses sosial maupun proses kognitif adalah sentral bagi pemahaman mengenai motivasi, emosi, dan tindakan manusia. Salah satu asumsi awal dan dasar teori sosial kognitif Bandura adalah bahwa manusia cukup fleksibel dan mampu mempelajari berbagai sikap, kemampuan, dan perilaku, serta cukup banyak dari pembelajaran tersebut yang merupakan hasil dari pengalaman tidak langsung. Teori ini lebih banyak digunakan untuk menerangkan terbentuknya perilaku. Namun demikian, oleh Tangney dan Dearing (2002) teori ini digunakan untuk menjelaskan keberhasilan dari proses sosialisasi yang dilakukan oleh agen sosialisasi (Tangney \& Dearing, 2002). Anak dapat bertindak sebagai pengobservasi tindakan orangtua termasuk saat orangtuanya melakukan tindakan yang keliru, pengalaman rasa bersalah, dan respon terhadap perilaku yang dapat diperbaiki. Orangtua memiliki kesempatan untuk menggunakan pengaruhnya untuk menjelaskan bagaimana anak-anaknya merasakan dan merespon kesalahan yang tidak terelakkan dan pelanggaran moral yang ditemui setiap hari. Anak juga memiliki kesempatan untuk mengobservasi apa yang dilakukan orangtua kemudian mencontoh yang sesuai dengan dirinya melalui kemampuan kognitif dalam dirinya.

Sejalan dengan hasil penelitian ini yang menunjukkan bahwa secara umum, emosi moral yang dirasakan remaja tergolong tinggi ( 65,2 persen dari $\mathrm{N}=936)$ dan sosialisasi emosi orangtua yang dirasakan oleh remaja pun temasuk dalam kategori tinggi (74,4 persen dari $\mathrm{N}=936$ ). Artinya, sebagaian besar remaja memiliki emosi moral yang kuat. Remaja mampu merespon dan mengevaluasi situasi moral yang memiliki tendensi prososial dan fokus pada kepentingan orang lain bukan dirinya sendiri. Remaja juga mampu mempersepsi dengan baik praktik- praktik pengasuhan yang merupakan proses sosialisasi yang dilakukan orangtua untuk menularkan atau mengajarkan emosi moral.

Sosialisasi emosi dari orangtua kepada anak akan berhasil apabila ada integrasi dari faktor eksternal dan faktor internal (Hastings, 2018). Perspective-taking sebagai faktor internal juga memiliki peran bagi emosi moral remaja. Perspective-taking dapat berpengaruh secara langsung terhadap emosi moral maupun berperan sebagai mediator antara sosialisasi emosi orangtua terhadap emosi moral. Sosialisasi emosi orangtua memiliki pengaruh yang semakin besar ketika dimediasi oleh perspectivetaking. Keberhasilan proses sosialisasi moral (nilai-nilai moral, aturan moral, perilaku moral, dan emosi moral) dapat dilakukan oleh orangtua melalui perspective-taking. Orangtua yang menanggapi situasi anak dengan menunjukkan ekspresi emosi yang baik dan menggunakan cara komunikasi yang hangat, dapat meningkatkan kemampuan persective-taking (Lerner \& Jovanovic, 2016). Orangtua yang membimbing anaknya dengan dukungan yang positif dan hangat akan membuatnya remaja mampu berpikir menggunakan sudut pandang orang lain. 
Orangtua yang mendorong anak-anak mereka untuk berpikir dan bertindak untuk dirinya sendiri dan berpikir rasional maka dapat mendorong anak-anak untuk menggunakan sudut pandang orang lain.

Perspective-taking merupakan

kemampuan kognitif yang menghasilkan pengetahuan tentang keadaan internal orang lain (Eisenberg et al., 2007) dan terdiri dari serangkaian sumber daya penting yang dapat digunakan anak dan remaja dalam upaya mengelola emosi dengan cara yang fleksibel dan adaptif (Selman \& Demorest, 1984). Kemampuan perspective-taking dapat digunakan untuk mengevaluasi peristiwa moral atau dilema moral sehingga dapat membantu mengembangkan emosi moral. Komunikasi dapat terjalin dengan efektif juga bila remaja mampu mengerti apa yang dimaksudkan orang lain atau mampu mendudukkan dirinya pada posisi orang tersebut. Komunikator dapat mempertimbangkan apa yang diketahui oleh pihak penerima informasi ketika memutuskan pesan yang akan disampaikan. Sebaliknya, penerima pesan pun juga diharapkan memiliki kemampuan perspective-taking agar dapat menyesuaikan isi dai informasi yang diterima dengan apa yang diyakini (Fussell \& Krauss, 1992; Krauss \& Fussell, 1991). Kemampuan ini membuat remaja mampu memahami dan mengerti apa yang disampaikan orangtua dan teman melalui sudut pandangnya. Apabila remaja mampu mengerti dan menggunakan cara pandang orang lain dalam dirinya maka akan mengerti alasan orang tua maupun teman mengajarkan emosi moral tertentu guna kebaikan bersama. Teman juga dapat membantu remaja dalam menginternalisasikan nilai-nilai moral dan emosi moral. Teman yang memberikan dukungan, yang memberi respon yang tepat, yang dapat diajak berdiskusi dapat membantu berkembangnya fungsi moral dalam diri remaja dengan kemampuan perspective-taking yang baik.
Penelitian ini menjadi berbeda dengan penelitian lainnya yang dilakukan di Indonesia karena fokus pada pentingnya meneliti variabel emosi moral sebagai variabel endogen (Y) pada remaja dari usia 12-18 tahun dan berlokasi di Semarang. Sedangkan penelitian lainnya memfokuskan emosi moral sebagai variabel eksogen (X) dengan partisipan usia 17-23 tahun yang berlokasi di Yogyakarta dan Jakarta. Selain itu, penelitian ini murni menggunakan metode kuantitatif non-eksperimen karena akan membangun model prediktif emosi moral untuk mengetahui faktor apa yang dapat memprediksi emosi moral. Sedangkan penelitian yang dilakukan oleh Septiana (2018) dan Widyarini (2016, 2017) menggunakan metode penelitian kuantitatif eksperimen. Teknik pengambilan sampel adalah multistage sampel agar sampel penelitian lebih representatif karena karena jumlah anggota populasi yang sesuai dengan karakteristik banyak dan tersebar di enam belas kecamatan di Semarang. Sedangkan penelitian lain yang dilakukan adalah menggunakan metode kuantitatif eksperimen

Berdasarkan pemaparan yang telah dijelaskan sebelumnya, maka model prediktif emosi moral secara umum dapat menjelaskan kontribusi akan peran pentingnya faktor kognitif dan faktor lingkungan yang dapat memprediksi emosi moral pada remaja. Melalui model prediktif ini tampak bahwa perspective-taking berpengaruh sebagai variabel mediator dalam mengembangkan emosi moral remaja. Remaja yang memiliki perspective-taking akan lebih mudah menerima informasi, masukan, atau pengetahuan baik dari orangtua maupun dari teman sebagai agen sosialisasi. Oleh karena itu, implikasi praktis yang dapat diberikan dari penelitian ini adalah sebagai dasar penyusunan strategi pencegahan pelanggaran moral. Strategi yang dapat dilakukan adalah melalui stategi pengasuhan orangtua yang tepat dalam menghadapi remaja sebagai 
upaya untuk meminimalkan pelanggaran moral yang dilakukan oleh remaja. Orangtua perlu tahu dan paham tentang emosi moral yang dapat dimanfaatkan untuk mencegah remaja melakukan pelanggaran moral. Strategi yang lainnya adalah pendampingan pada remaja dengan mengenalkan dan mengajak remaja untuk sadar terus dengan emosi moral yang dimiliki agar dapat mencegah perilaku pelanggaran moral.

Secara keseluruhan, penelitian ini telah membuktikan model pengukuran dan model struktural yang didukung oleh data di lapangan. Namun, penelitian ini memiliki keterbatasan, yaitu hanya menggunakan metode penelitian kuantitatif saja dengan alat ukur model skala psikologi (dengan pilihan jawaban yang sudah ditentukan) dan tidak menggali informasi lain untuk melihat dinamika psikologis dengan cara wawancara atau dengan memberikan pertanyaan terbuka. Oleh karena itu, kedalaman analisisnya masih kurang dan kurang mampu mengungkap faktor-faktor lain yang kemungkinan dapat memengaruhi emosi moral remaja misalnya pengaruh atau dukungan teman sebaya, pengaruh guru, iklim sekolah, regulasi diri, atau pengaruh dari budaya setempat.

\section{SIMPULAN}

Berdasarkan pemaparan di atas, dapat disimpulkan bahwa sosialisasi emosi orangtua yang dipersepsi oleh remaja dapat memengaruhi emosi moral secara langsung maupun secara tidak langsung melalui perspective-taking. Berdasarkan keterbatasan penelitian, maka saran bagi peneliti selanjutnya adalah menambahkan metode kualitatif dengan wawancara maupun pertanyaan terbuka untuk memperdalam dinamika psikologis hasil penelitian yaitu antara sosialisasi emosi orangtua, perspectivetaking, dan emosi moral.

\section{UCAPAN TERIMA KASIH}

Penulis mengucapkan terima kasih kepada Direktorat Penelitian dan Pengabdian kepada Masyarakat, Direktorat Jenderal Penguatan Penelitian dan Pengembangan, Kementerian Riset, Teknologi, dan Pendidikan Tinggi (Program Hibah Penelitian Disertasi Doktor).

\section{DAFTAR PUSTAKA}

Bennett, D. S., Sullivan, M. W., \& Lewis, M. (2010). Neglected children, shameproneness, and depressive symptoms. Child Maltreatment, 15(4), 305-314. doi:10.1177/1077559510379634

Dunn, J. (n.d.). The Development of Individual Differences Antecedents and Sequelae, 303-320.

Eisenberg, N., Cumberland, A., \& Spinrad, T. L. (1998). Parental socialization of emotion. Psychol Inq, 9(4), 241-273.

Eisenberg, N., Fabes, R. A., \& Spinrad, T. L. (2007). Prososial Development. Handbook of Child Psychology, 73. doi:10.4324/9781315560984-2

Fussell, S. ., \& Krauss, R. M. (1992). Coordination of knowledge in Communication: Effects of speakers assumptions about what others know. Journal of Personality and Social Psychology, 62(3), 378-391.

Ghozali, I., \& Fuad, S. (2014). Structural equation modeling. Teori, konsep, dan aplikasi dengan Program Lisrel 9.10. (Ed Keempat). Semarang: Badan Penerbit Universitas Diponegoro.

Greene, J., \& Haidt, J. (2002). How (and where) does moral judgment work? Trends in Cognitive Sciences, 6(12), 517-523.

Haidt, J. (2003). The Moral Emotions. In R. J. Davidson, K. R. Scherer, \& H. H. Goldsmith (Eds.), Handbook of affective 
sciences (pp. 852-870). Oxford University Press. doi:10.1093/mnras/stx1358

Hair, J.F., Hult, G.T.M., Ringle,C.M., \& Sarstedt,M.( 2017).A Primer on Partial Least Squares Structural Equation Modeling (PLS-SEM) (2th Ed.).Los Angeles: SAGE Publications, Inc.

Halberstadt,A.G.(1986).Family socialization of emotional expression and nonverbal communication stles and skills. Journal of Personality and Social Psychology,51(4),827-836. doi:10.1037/0022-3514.51.4.827

Hastings, P. D. (2018). The socialization of emotion by parents: Following Saarni's legacy. European Journal of Developmental Psychology, 15(6), 694710.

doi:10.1080/17405629.2018.1482210

Hawley, P. H. (2003). Strategies of control, aggression, and morality in preschoolers: An evolutionary perspective. Journal of Experimental Child Psychology, 85(3), 213-235. doi:10.1016/S0022-0965(03)00073-0

Henslin. (2013). Chapter Three: Socialization. Essentials of Sociology.

Higgins,E.T. (1987). Self discrepancy: A Theory Relating Selft and Affect. Psychological Review, 94(3), 319-340.

Hoffman, M. L. (2000). Introduction and Overview. In Empathy and moral development: Implications for caring and justice (pp. 1-28). USA: The Press Syndicate of the University of cambridge. doi:10.1017/CBO9780511805851

Johnston, M., \& Krettenauer, T. (2011). Moral self and moral emotion expectancies as predictors of anti- and prosocial behaviour in adolescence: A case for mediation? European Journal of Developmental Psychology, 8(2), 228-243. doi:10.1080/17405621003619945

Karmakar, R. (2015). Does parenting style influence the internalization of moral values in children and aAdolescents? Psychological Studies, 60(4), 438-446. doi:10.1007/s12646-015-0338-2

Klimes-Dougan, B., \& Zeman, J. (2007). Introduction to the special issue of social development: Emotion socialization in childhood and adolescence. Social Development, 16(2), 203-209. doi:10.1111/j.1467-9507.2007.00380.x

Konchanska, G., Koenig, J. L., Barry, R. A., Kim, S., \& Yoon, J. (2010). Children's conscience during toddler and preschool years, moral self, and a competent, adaptive developmental trajectory. Dev. Psychology, 46(5), 1320-1332. doi:10.1037/a0020381

Krauss, R. M., \& Fussell, S. R. (1991). Perspective-taking in communication: Representations of others' knowledge in reference. Social Cognition, 9, 2-24.

Krebs, D. L. (2008). Morality: An Evolutionary Account. Perspectives on Psychological Science, 3(3), 149-172. doi:10.1111/j.1745-6924.2008.00072.x

Krettenauer, T., \& Eichler, D. (2006). Adolescents' self-attributed moral emotions following a moral transgression: Relations with delinquency, confidence in moral judgment and age. British Journal of Developmental Psychology, 24(3), 489506. doi:10.1348/026151005X50825

Lagattuta, K. H., \& Thompson, R. A. (2007). The development of self-conscious emotions: Cognitive processes and social influences. In J. L. Tracy, R. W. Robins, \& J. P. Tangney (Eds.), The selfconscious emotions: Theory and research (p. 91-113). Guilford Press.

Lazarus, R S. (1991). Emotion and adaptation. Oxford : Oxford University Press 
Leenders, I., \& Brugman, D. (2005). Moral/non-moral domain shift in young adolescents in relation to delinquent behaviour. British Journal of Developmental Psychology, 23(1), 6579. doi:10.1348/026151004X20676

Lerner,R.M. \& Jovanovic,J.(2016). Cognitive and Moral Development, Academic Achievement in Adolescence. USA : Routledge

Lewis, M. (2008).Self-conscious emotions: Embarrassment, pride, shame, and guilt. In M.Lewis, J.M. Haviland-Jones, L.F.Barret.(2008), Handbook of Emotions (pp). New York: TheGuilford Press

Malti, T., Eisenberg, N., Kim, H., \& Buchmann, M. (2013). Developmental trajectories of sympathy, moral emotion attributions, and moral reasoning: The role of parental support. Social Development, 22(4), 773-793. doi:10.1111/sode.12031

Malti, T., Keller, M., Gummerum, M., \& Buchmann, M. (2009). Children's moral motivation , sympathy, and prosocial behavior. Child Development, 80(2), 442-460.

doi:10.1109/ICCA.2017.8003213

Malti, T., \& Krettenauer, T. (2013). The relation of moral emotion attributions to prosocial and antisocial behavior: A meta-analysis. Child Development, 84(2), 397-412. doi:10.1111/j.14678624.2012.01851.x

Malti, T., \& Ongley, S. F. (2015). The Development of Moral Emotions and Moral Reasoning. Handbook of Moral Development.

doi:10.4324/9780203581957.ch8

Meesters, C., Muris, P., Dibbets, P., Cima, M., \& Lemmens, L. (2017). On the lLink between perceived parental rearing behaviors and self-conscious emotions in adolescents. Journal of
Child and Family Studies, 26(6), 15361545. doi:10.1007/s10826-017-0695-7

Morris, A. S., Silk, J. S., Steinberg, L., Myers, S. S., \& Robinson, L. R. (2007). The role of the family context in the development of emotion regulation. Social Development, 16(2), 361-388. doi:10.1111/j.1467-9507.2007.00389.x

Parisette-Sparks, A., Bufferd, S. J., \& Klein, D. N. (2015). Parental predictors of children's shame and guilt at aAge 6 in a multimethod, longitudinal study. Journal of Clinical Child and Adolescent Psychology, 1-11. doi:10.1080/15374416.2015.1063430

Pauwels, L. J. R., \& Svensson, R. (2015). Schools and child antisocial behavior: In search for mediator effects of schoollevel disadvantage. Sage Open, 1-13. doi:10.1177/2158244015592936

Piaget, J. (1965). The Moral Judgment of The Child. (M. Gabain, Ed.). Illinois: The Free Press.

Pui-Ki, A. (2001). Young children's development of self-conscious eEmotions: Guilt, shame and embarrassmen. The Chinese University of Hong Kong.

Prinz,J.(2007).The emotional construction of morals. new York: Oxford University Press

Ramdhani, N. (2016). Emosi moral dan empati pada pelaku perundungan-siber, 43, 66-80. doi:10.22146/jpsi.12955.

Santrock, J.W.(2016).A Topical Approach to Life-Span Development. (ed 8). New York : Mc.Graw-Hill Education.

Santrock, J.W. (2007). Adolescence. (ed 11). New York : Mc.Graw-Hill.

Selman, R. L., \& Demorest, A. P. (1984). Observing troubled children's interpersonal negotiation strategies: implications of and for a developmental 
model. Child Development, 55(1), 288$304 . \quad$ doi:10.1111/j.14678624.1984.tb00292.x

Septiana, E. (2018). Mekanisme Emosi Moral dan Identitas Moral Berperankah dalam Kecurangan akademik?. Disertasi. Naskah tidak dipubikasikan. Jakarta: Universitas Indonesia. https://psikologi.ui.ac.id/2018/07/10/em osi-moral-dan-identitas-moralberperankah-dalam-kecuranganakademik-mahasiswa/.

Sheikh, S., \& Janoff-Bulman, R. (2010). Tracing the self-regulatory bases of moral emotions. Emotion Review, 2(4), 386-396. doi: $10.1177 / 1754073910374660$

Shipman, K. ., Zeman, J., Nesin, A. E., \& Fitzgerald, M. (2003). Children's strategies for displaying anger and sadness: What works with whom? Merrill-Palmer Quarterly, 49(1), 100122.

Smith, C. A., \& Ellsworth, P. C. (1985). Patterns of cognitive appraisal in emotion. Journal of personality and social psychology. doi:10.1037//00223514.48.4.813

Spruit, A., Schalkwijk, F., Vugt, E. Van, \& Stams, G. (2016). The relation between self-conscious emotions and delinquency: A meta-analysis. Aggression and Violent Behavior, (April 2018). doi:10.1016/j.avb.2016.03.009

Stams, G. J., Brugman, D., Dekovic, M., van Rosmalen, L., van der Laan, P., \& Gibbs, J. C. (2006). The moral reasoning of juvenile delinquents: A Metaanalysis. $J$ Abnorm Child Psychol, 34(Oktober), 697-713. doi:10.1007/s10802-006-9056-5

Stests, J.E. \& Turner, J.H.(2006). Handbook of the sociology of emotions. United States of Amerika : Springer Science+Business Media,LLC.
Svensson, R., Pauwels, L. J. R., Weerman, F. M., \& Bruinsma, G. J. N. (2017). Explaining individual changes in moral values and moral emotions among adolescent boys and girls: A fixedeffects analysis. European Journal of Criminology, 14(3), 290-308. doi:10.1177/1477370816649626

Tangney, J.L., Stuewig, J., \& Mashek, D. J. (2007). Moral emotions and moral behavior. Annuan Rev Psychology, 58, 345-372.

doi:10.1146/annurev.psych.56.091103.0 70145 .

Tangney, J.L., \& Tracy, J. (2011). Selfconscious emotions. In Handbook of Self and Identity. New York: Guilford Press.

Tangney, J. P., \& Dearing, R. L. (2002). Shame and guilt. New York, NY: Guilford Press

Tracy, J.L. \& Robins, R.W. (2007). The self in self-conscious emotions: A cognitive appraisal approach, In J.L. Tangney, R.W.Robins, \& J.P. Tangney, The SelfConscious Emotions Theory and Research (pp.3-20). New York: the Guilford Press.

Widyarini, I. (2016). The Role of Positive Moral Emotions (Elevation, dmiration and Happiness) in Ethical Decision Making. Prosiding Temu Ilmiah Nasional IPPI.Semarang: IPPI

Widyarini, I. (2017). The role of negative moral emotions (anger and disgust) in ethical decision making. Proceeding 8th International Conference of Asian Association of Indigenous and Cultural Psychology (ICAAIP 2017).Advances in Social Science, Education and Humanities Research (ASSEHR), volume 127

Wikström, V. (2015). Emotion Transfer Protocol. Tesis, 82. Retrieved from https://aaltodoc.aalto.fi/handle/1234567 $89 / 18063$ 
Zeman, J., Cassano, M., \& Adrian, M. C. (2017). Socialization influences on children's and adolescents' emotional self-regulation processes. Handbook of Self-Regulatory Processes in Development, (10872). doi:10.4324/9780203080719.ch5 